\title{
Study Skills among High School Students: An Exploratory Study of Private High Schools in Albania
}

\author{
Ana Uka, MSc. \\ Lecturer, Department of Educational Sciences, Counseling Psychology and Education Program, \\ Beder University, Tirana, Albania, auka@beder.edu.al
}

\section{Doi:10.5901/jesr.2013.v3n7p17}

\section{Abstract}

A good education can be provided through the committment and action of students, teachers and administrators. Students' effective learning can be encouraged and enhanced through the development of the students' organization skills. Evidence shows that many high school students fail to do well academically because of a lack of their study skills. This work is conducted to report on an exploratory study of six schools in Albania where their key characteristics are found to be important to these schools' success. The data are obtained from a close-ended survey in a Likert type scale with adequate validity and reliability (Cronbach's alpha=.88). The sample consisted of $N=255,11$ th and 12 th grade students ( $N=116$ male, $45.5 \%$ and $\mathrm{N}=138$ female, 54.1\%) from eight high schools in Albania. Results showed that, female students were significantly different from male students on: I take notes as I read textbook assignments $(p<.01)$; When I don't understand something, I get help from my classmates, toturs and instructors ( $p=.025)$; and I can easily identify what I have learned and what I have not yet learned before I take a test ( $p=.018$ ). We found no correlation between parental education level, number of children in the family and students' study skills. At the end implications and recommendations of these findings are discussed for further research on the study skills of high school students.

Keywords: study skills, high school, students, Albania.

\section{Introduction}

The search for unknown throughout history brought us to the interrelation between school, teacher, and students; as it has always been a need for human beings to quench their thirst for learning more and more. However, environmental issues, different talents, variety of the goals, methodologies used in teaching or learning, and most importantly technology are some of the factors that determine the level of teaching and learning on each individual.

A good education can be provided through the committment and action of students, teachers and administrators. Obtaining a good education and being successful at school is very important in our life. Being successful at school is related to a high level of study skills which should be practiced and developed by the students.

Learning or studying is an ability or a skill. Everyone is different from the others and every student approaches the learning process differently. Every student has a unique learning style or learning method through which the student tries to study hard and succeed academically. Students' effective learning can be encouraged and enhanced through the development of the students' organization skills. Evidence shows that many high school students fail to do well academically because of a lack of their study skills.

This work is conducted to report on an exploratory study focused on the $11^{\text {th }}$ and 12 grade high school students found in eight private schools in Albania whose key characteristics are found to be integral to these schools' success. The research questions of this study are: 1) Are there any gender differences in terms of the study skills among high school students? 2) Is there any relationship between the students' study skills and parental education level and, 3) Is there any relationship between the number of children in the family and the students'study skills?

\section{Learning approaches, school bonding and the students' academic success}

One of the cornerstones of successful students' learning is their ability to use appropriate learning approaches. Awareness and orchestration of learning approaches are central to self-regulation of learning - a key concept in explaining effective learning (Malie \& Oriah, 2012). There are volumes of research investigating the relationship between best practices in teaching by teachers and best practices in learning by students. It is important to consider how the 
observed teacher behaviors and student - teacher interactions can be generalized to foster positive learning environments in traditional high school classrooms (Ratcliff et al., 2012). The role of the school is one of the key components in providing a better setting for learning and teaching; a sense of attachment to the school on the student side would bring fruitful results and when students feel connected to or have strong bonds to their schools, they are more likely to experience academic success. Evidence shows that, school bonding is multidimensional and it includes four specific components: (a) attachment to school, (b) attachment to teachers and school personnel, (c) school commitment (comprising both beliefs and behaviors), and (d) school involvement (Bryan et al., 2011). The findings of this study demonstrated that all four components of school bonding affect students' academic achievement at some point during high school, whether the effects are proximal or distal. Yet only about $50 \%$ of the youth in schools report feeling connected to or engaged in school (Blum, 2005 and Bryan et al., 2011).

On the other hand, students with different needs may require special approaches and care. Especially, if the students are gifted, extra effort is needed to provide appropriate school setting, and qualified teachers to approach their possibly hidden talents. Developing an appropriate learning environment is a critical factor in the successful instruction of the gifted students. Hennessey (2004), noted that close attention must be paid to creating appropriate learning environments if student motivation, creativity, and special talents are to be augmented. Another study shows that, highability students respond to classroom environments that are active and engaging, despite the use of whole-class grouping, direct instruction, and low-level questions. These students performed well in quickly paced, stimulating environments where the teachers mentally engaged (interacted) with students through direct instructional methods (Ratcliff et al., 2012). However, students' learning approaches and strategies are not merely enough to achieve academic success or a satisfactory learning (Malie \& Oriah, 2012). A holistic approach and strategies are needed to gain a better performance: Studies have also revealed that students use different learning approaches and strategies and these in turn influence their academic achievement. This is reflected also in with the following words - Talents would bloom in the bosom of fertile fields where needed receives hislher needs, and the addresser finds fertile grounds to sow hislher seeds.

\section{Learning methods}

Knowledge acquisition can be accomplished through a successful use of the learning methods. Learning methods is an educational process that leads the students to the way how to explore, understand and practice the knowledge of a specific field. There are three types of learning methods including: visual (by sight), auditory (by hearing), or hands on (by doing) (SOAR Program, 2002). Depending on how we learned the activity, we will have a fair idea of what learning method we have. During the comprehension of such activities, we use all the learning methods. In fact, we use all our senses to learn and to observe the world around us, but each of us has a tendency to learn more heavily on one of the three learning methods - visual, auditory, or hands on. Visual learning style includes using colorful pens or highlighters, looking at the pictures or graphs, using flashcards and getting notes. Auditory learners process and remember information best when they hear it and repeat it. Kinesthetic or hands on learners need hands on activities by frequently using the sense of touch. Study strategies can be better improved once we develop and integrate all the learning methods.

There are several factors that influence students' learning. One of the most important key factors is motivation. Motivation is considered as a useful tool for the teachers and parents to encourage the students to work hard. If the teacher manages to motivate the students (i.e this chapter is very easy, or this is the easiest topic in this lesson), they will start studying and succeed in at least half of it or more. Some findings indicate that students have different levels of motivation, different attitudes about teaching and learning and different responses to specific classroom environments and instructional practice (Felder \& Brent, 2005 and Malie \& Oriah, 2012).

Loranger (1994), examined the study strategies of successful and unsuccessful high school students of grade 11 , to determine if successful students would differ from unsuccessful students, in the quality of their information processing. It was expected that good learners would use different study skills requiring greater cognitive effort, such as note-taking, summarizing, and outlining. She found that successful students were more active, purposeful, and flexible in their strategy use. Although the unsuccessful students were generally less efficient in their use of learning strategies, they were satisfied with their academic performance. The successful students were motivated to succeed and did use strategies to accomplish this goal. The less successful students were not only less apt to access strategies on their own, but also lacked self-knowledge of inefficient strategy use. 


\title{
4. Study skills
}

Students' effective learning can be encouraged and enhanced through the development of their study skills. Study skills include several abilities such as: 1) understanding visual representations of information; 2) previewing a text before reading; 3) locating information; 4) taking notes; 5) taking tests; 6) listening and reading with attention; 7) and intention to learn.

1. Visual sense is one of the most powerful ones and understanding visual representations of information allows the student to see, explore, and understand large amounts of information in a different way.

2. Previewing a text before reading is an important part of the pre-reading process because, it activates the reader's schema or background knowledge on a topic and helps the reader make connections to the material before they read it.

3. Locating information is an important skill practiced especially when we need to navigate, analyze and draw conclusions based on information from a variety of sources.

4. Note taking strategies help the students draw a clear picture of what they have heard and capture all the information needed for later study. They also encourage the students to concentrate and actively listen and learn during the class time. Note taking strategies include coming prepared to the class, starting a new page for each class, writing down the major ideas, leaving enough space between notes, using graphic organizers or pictures, reviewing notes before the lesson and after the lesson and getting notes from missed classes. (Middleborough High School Guidance Department, MA).

5. Taking tests is an important method of measuring the comprehension of the material. In order to succeed in the tests, students should learn test-taking skills, develop their strategic thinking and comprehend on the course content.

6. Listening and reading with attention is related to the encoding and retrieval functions of the memory. They are also an important part of the learning process. Improved attending skills can stimulate the students' class participation, reading carefully, completion on time of individual and group assignments and effective exam preparation.

7. Intention to learn is the aim or the learning objective that makes the students understand what they want to learn and helps them become more engaged with the class activities. Learning intentions should have a focus on the knowledge, skills and understanding and, they should serve the demands of the students. During the learning process, it is important to distinguish between knowing and understanding. In her comments following a conversation hosted by Derek Young at TED, Annette White (2012), claims that:

\begin{abstract}
"Knowledge can be applied but only understanding creates new ideas which present new problems which require new solutions. To do that, we need brains which can learn to acquire knowledge and minds that can understand what that knowledge means and its significance, validity and relevance. Knowing how we learn and what 'content' helps us to practice different kinds of learning is the metacognitive aspect of learning which is just beginning to make an impact."
\end{abstract}

Having the desire to succeed and knowing how to effectively learn, is the first step in developing effective study habits and perform better at school. According to the S.O.A.R program developed by Mayland Community College (2002), good study habits include many different skills: time management, selfdiscipline, concentration, memorization, and organization. Time management tips shortly include setting goals, recording assignments, making to do list daily, using spare time wisely, finding right time and place to study well and, getting plenty of sleep when it is needed (Middleborough High School Guidance Department, Massachusetts). Selfdiscipline includes: willpower, hard work and persistence. It is the product of persisted willpower or the structured thought used automatically that leads to success. Concentration depends on how much control do we have in our mind. It is focused on getting the mind on a task or several tasks while trying to stay away from distractions. Improving concentration skills can result in a successful learning process. Memory is a complicated process whereby images, sounds, ideas, words, phrases, and even times and places are encoded, so we can recall them later (Armstrong, 2010). Memorization is a skill that can be learned and the more you train yourself, the more confident, prepared and less anxious you are. A successful student can manage to have a good organization of his/her work and effectively use basic study skills. They can create their own systems for organizing, processing, and comprehending what they read or hear in the class; planning homework and long term assignments; studying for tests; and determining effective test-taking strategies (Sedita, 1999). 


\section{Methods}

Participants. This study was conducted to investigate the students' study skills and strategies that lead them to academic success. The students, who participated in this study, come from eight private high schools found in different cities of Albania. These schools are considered to be the most successful ones across the country. Evidence shows that, the graduates from these schools continue their academic success even during their further studies and later in their professional career. The aim of this study was to reveal these students' study skills and beyond these, what makes them become successful and a role model for the other students studying in the other schools in Albania. As shown in Table 1., the sample consists of $\mathrm{N}=255$ including 116 males (45.5\%) and 138 females (54.1\%).

Table 1. Distribution Categories by Gender

\begin{tabular}{|c|c|c|}
\hline Gender & Frequency & Percentage (\%) \\
\hline Male & 116 & 45.5 \\
\hline Female & 138 & 54.1 \\
\hline Total & 255 & 100.0 \\
\hline
\end{tabular}

Measurement tools. The data was collected by using the "Study Skills Survey", a close-ended survey which aims at helping the students assess their academic skills and it provides a general idea of how to view their abilities. This survey was obtained electronically from "Freshmen Learning Center", which is an adapted version from a model at University of Central Florida. The items $(n=51)$ of this survey were forced choice and a five-point $(1=$ Almost always to $5=$ Almost never) Likert type scale was used to measure the respondent's level of study skills. The questionnaire consisted of six parts: 1) "Textbook Reading Skills" (8 questions), 2) "Notebook Skills" (5 questions), 3) "Memory Skills" (9 questions), 4) "Test Preparation Skills" (13 questions), 5) "Concentration Skills" (10 questions) and 6) "Time Management Skills"(6 questions). In the first page, brief information is provided for the respondents about the reason of using this questionnaire and then, demographic information related items are included in the first page of the questionnaire.

Validity and reliability. For the internal consistency and reliability we measured the Cronbach's alpha, which is a method of estimating internal reliability. As shown in Table 2., we received a Cronbach's alpha coefficient of 0.88 for 51 items included in the questionnaire. Considering that Cronbach's alpha should be greater than 0.6 , this questionnaire is reliable.

Table 2. Cronbach's Alpha

\begin{tabular}{|c|c|}
\hline \multicolumn{2}{|c|}{ Reliability statistics } \\
\hline Cronbach's Alpha & N of Items \\
\hline .88 & 51 \\
\hline
\end{tabular}

Data collection. In this study, 255 questionnaires were filled out by $11^{\text {th }}$ and $12^{\text {th }}$ grade high school students from eight private high schools in different cities of Albania. The students were provided brief information about the aim of the study, they were assured confidentiality and they were thanked about their willingness to participate in this study. The survey took about 7-10 minutes to be completed before the lecture time or during the break. Completed questionnaires were collected by the instructor of a certain discipline in each high school and they were returned to our department. Totally, 255 surveys were completed and returned to the department.

Data analysis. Descriptive statistics were used to describe the sample. The responses received from this study were coded as 5, 4, 3, 2, 1. The data was analyzed using the independent samples T-test of IBM SPSS Statistics 20. for windows to compare the study skills between male and female students, and check if the difference between the mean values of the test variable for one group differs significantly from the mean value of that variable for the second group of the respondents. Bivariate Pearson correlation analysis was computed to find out if there is an association between the respondent's parental education level and number of children in the family and their study skills. In Table 3., it is shown that more than half of the respondents $(60.0 \%)$ were at 11 th grade. 
Table 3. Distribution Categories by Grade

\begin{tabular}{|c|c|c|}
\hline Grade & Frequency & Percentage (\%) \\
\hline 11th Grade & 153 & 60.0 \\
\hline 12th Grade & 100 & 39.2 \\
\hline Missing & 2 & 0.8 \\
\hline Total & 255 & 100.0 \\
\hline
\end{tabular}

As we can see from Table 4., the majority of 11 th grade students $(n=85)$, come from families with two children. The majority of the high school students in total $(n=119)$, have one sibling.

Table 4. Distribution Categories by Grade * Number of children in the family

\begin{tabular}{|c|c|c|c|c|c|c|}
\hline Grade & $\begin{array}{c}\text { One } \\
\text { child }\end{array}$ & $\begin{array}{c}\text { Two } \\
\text { children }\end{array}$ & $\begin{array}{c}\text { Three } \\
\text { children }\end{array}$ & $\begin{array}{c}\text { More than } \\
\text { three }\end{array}$ & Missing & Total \\
\hline 11th grade & 15 & 85 & 46 & 7 & 0 & 153 \\
\hline 12th grade & 11 & 34 & 35 & 19 & 2 & 102 \\
\hline Total & 26 & 119 & 83 & 26 & 2 & 255 \\
\hline
\end{tabular}

From Table 5., we can see that the highest level of education of the majority of the parents $(74.5 \%)$ is the high school diploma. Only $16.9 \%$ of the respondents had both parents with a doctoral degree.

Table 5. Crosstabulation of Mother's education level * Farther's education level

\begin{tabular}{|c|c|c|c|c|c|c|c|c|}
\hline & \multicolumn{6}{|c|}{ Farther's education level } & \multirow[b]{2}{*}{ Total } \\
\hline & & \begin{tabular}{|c|} 
Elementary/Middle \\
School Diploma
\end{tabular} & \begin{tabular}{|c|} 
High School \\
Diploma
\end{tabular} & $\begin{array}{c}\text { Bachelor } \\
\text { Degree }\end{array}$ & \begin{tabular}{|l} 
Master \\
Degree
\end{tabular} & $\begin{array}{l}\text { Doctoral } \\
\text { Degree }\end{array}$ & Missing & \\
\hline \multirow[t]{6}{*}{$\begin{array}{l}\text { Mother's } \\
\text { education level }\end{array}$} & $\begin{array}{l}\text { Elementary/Middle } \\
\text { School Diploma }\end{array}$ & 23 & 19 & 4 & 0 & 0 & 0 & 46 \\
\hline & High School Diploma & 12 & 52 & 21 & 13 & 5 & 0 & 103 \\
\hline & Bachelor Degree & 2 & 6 & 29 & 12 & 3 & 1 & 53 \\
\hline & Master & 1 & 9 & 4 & 15 & 5 & 0 & 34 \\
\hline & Doctoral Degree & 0 & 1 & 2 & 5 & 11 & 0 & 19 \\
\hline & Total & 38 & 87 & 60 & 45 & 24 & 1 & 255 \\
\hline
\end{tabular}

\section{Results}

Results showed that, there were no significant differences between male and female high school students in their study skills. However, as shown in Table 6., we found that female students were significantly different from male students on: I take notes as I read textbook assignments $(p<.01)$; When I don't understand something, I get help from my classmates, toturs and instructors $(p=.025)$; and I can easily identify what I have learned and what I have not yet learned before I take a test $(p=.018)$.

Table 6. Comparison of Female and Male High School Students on Study Skills

\begin{tabular}{lccccc} 
( $n=138$ females and $n=116$ males) & & & & & \\
\hline Variable & $\mathrm{M}$ & $\mathrm{SD}$ & $\mathrm{t}$ & $\mathrm{df}$ & $\mathrm{P}$ \\
\hline Taking notes on textbook assignments & & & -3.66 & 214.2 & $\mathrm{p}<.01$ \\
$\begin{array}{l}\text { Female } \\
\text { Male }\end{array}$ & 4.00 & 1.02 & & & \\
$\quad$ Getting help from classmates, tutors and & & 1.32 & & & \\
$\begin{array}{l}\text { instructors } \\
\text { Female }\end{array}$ & & & -2.23 & 252 & .025 \\
Male & 4.38 & 3.63 & & & \\
$\quad \begin{array}{l}\text { Easily identifying what you have learned } \\
\text { befor a test }\end{array}$ & 3.59 & 1.30 & & & \\
Female & & & -2.39 & 207.23 & .018 \\
Male & 4.12 & 0.95 & & & \\
\hline & 3.78 & 1.30 & & & \\
\hline
\end{tabular}


There were no significant differences between 11th and 12th grade high school students in their study skills. However, as shown in Table 7., we found that 11th grade students were significantly different from 12th grade students on: I compare notes with one or more other students to check completeness and accuracy $(p=.023)$; I use mnemonics, a formula or rhyme to help me remember ideas $(p=.001)$; I exercise daily $(p=.040) ;$ I write out short-term and long-term academics goals each semester $(p=.046)$.

Table 7. Comparison of 11th Grade and 12th Grade High School Students on Study Skills

\begin{tabular}{lccccc} 
(n=153 11th Grade and n=100 12th Grade Students) & \multicolumn{7}{c}{} \\
\hline Variable & $\mathrm{M}$ & $\mathrm{SD}$ & $\mathrm{t}$ & $\mathrm{df}$ & $\mathrm{P}$ \\
\hline Compare notes to check completeness and accuracy & & & 2.29 & 236.84 & .023 \\
11th Grade & 2.94 & 1.47 & & & \\
12th Grade & 2.55 & 1.23 & & & \\
Using mnemonics to remember ideas & & & -3.25 & 238.54 & .001 \\
11th Grade & 3.09 & 1.46 & & & \\
12th Grade & 3.63 & 1.19 & & & \\
I exercise daily & & & 2.06 & 233.2 & .040 \\
11th Grade & 3.29 & 1.38 & & & \\
12th Grade & 2.96 & 1.18 & & & \\
Writing short and long-term goals & & & 2.01 & 152.03 & \\
11th Grade & 29.01 & 159.46 & & & \\
12th Grade & 3.11 & 1.27 & & & \\
\hline
\end{tabular}

Bivariate Pearson correlation analyses showed that, there was no association between maternal education level and the students' study skills. On the other side, a strong positive correlation was found between maternal education level and the students' study skill in: "I write out short-term and long-term academics goals each semester", $r(255)=.135, p<.05$ and "I think about material that could be on exams and quizes when I am not studying", $r(255)=-.213, p=.001)$. We found no correlation between paternal education level and students' study skills. However, a strong positive correlation was found between paternal education level and the students' study skill only in: "I take notes in lectures", $r(255)=-.127$, $p=.042$. Next, the correlation analyses showed that there is no correlation between the number of children in the family and the students'study skills except in one study skill such as: "I take notes in lectures", $r(255)=-.187, p=.003$.

\section{Recommendations and Conclusions}

This study investigated possible associations between some demographic data obtained from the students and their study skills. No relationship was found between Parental Education Level and Number of Children in the Family and Study Skills. No differences were found also between male and female students in their study skills. The results showed that the students scored high on most of the items of the study skills. With respect to this, these students' academic success can be attributed to their personal efforts and their teachers' persistence on motivating the students to discover the most efficient and effective study techniques and strategies. These results are in line with other findings which suggest that learning different study techniques and improving the study skills can help the students become more successful and in tune with the most efficient methods of learning. Through this insight, the students understand the learning style and which technique works best and which one is the least effective. By maximizing the most effective learning methods, the students will be able to learn as much as they can in the classroom and through their studying to become more successful at school.

There are limitations in this study in many respects - because of the small sample and using only one questionnaire. No interview with both the students and the teachers and academic records were received from each student. Regarding these limitations, more research is needed to be conducted with larger samples by using not only student reported data but also teachers' and parents' reported data, to better understand the students' study skills.

\section{References}

Armstrong, E. (2010). Memorization and practice. York University. Retrieved from: http://www.yorku.ca/earmstro/courses/2nd_yr Imemorization_and_practice.pdf

Blum, R. (2005). School connectedness: Improving students' lives. Retrieved from: http://cecp.air.org/download/MCMonograph- 
Final.pdf.

Bryan, J., Thomas C. M., Gaenzle, S., Kim, J., Lin C. H. and Na, G. (2011). The Effects of School Bonding on High School Seniors' Academic Achievement. Journal of Counseling \& Development.

"Developing Effective Study Habits", S.O.A.R. Program, Mayland Community College.

Felder, R. M. \& Brent, R. (2005). Understanding Student Differences. Journal of Engineering Education 94(1), 57-72.

Hennessey, B. A. (2004). Developing Creativity in Gifted Children: The Central Importance of Motivation and Classroom Climate. Wellesley, MA: Wellesley College.

Loranger, A. L. (1994). The Study Strategies of Successful and Unsuccessful High School Students. Journal of Reading Behavior 26(4), 347-360.

Malie, S. \& Oriah, A. (2012). Bridging the gaps between learning and teaching through recognition of students' learning approaches: A case study. Research in Education 87

Ratcliff, N. J., Jones, C. R., Costner, R. H., Knight, C., Disney, Savage-Davis, G., E., Sheehan, H. and Hunt, G. H. (2012). No Need to Wait for Superman: A Case Study of One Unique High School. Journal for the Education of the Gifted 35(4), 391-411.

Sedita, J. (1999). Helping Your Child with Organization and Study Skills. Retrieved from: http://www.Idonline.org/article/5884/

Study Skills for High School Students. (2009). MA: Middleborough High School Guidance Department.

Study Skills Group, Upper St. Clair High School Counseling Department Pennsylvania, USA

Derek, Y. (2012). Does Education teach us to memorize information, instead of understanding it, or is memorizing important for future use? Annette White. Retrieved from: http://www.ted.com/conversations/10879/does_education_teach_us_to_mem.html 